\title{
Principais causas de absenteísmo por professores: revisão integrativa de literatura
}

\author{
Main teacher absentiment causes: integrative literature review
}

\begin{abstract}
Causas principales del ausentismo de los profesores: revisión de la literatura integradora
\end{abstract}
Tatiana Naiana Rodrigues dos Santos Porto1, Tatyanne Silva Rodrigues ${ }^{1 *}$, Mara Monize Pinheiro Mendes $^{2}$, Raisa Mikahil Monteiro de Sousa ${ }^{3}$, Gaubeline Teixeira Feitosa ${ }^{1}$, Isaura Danielli Borges de Sousa ${ }^{4}$, Nisleide Vanessa Pereira das Neves ${ }^{4}$, Leonilson Neri dos Reis ${ }^{1}$.

\section{RESUMO}

Objetivo: Identificar na literatura as principais causas de absenteísmo por professores. Métodos: Revisão integrativa, a coleta dos dados foi realizada no período de julho a novembro de 2019, utilizando via Biblioteca Virtual em Saúde (BVS) as bases de dados Literatura Latino-Americana em Ciências de Saúde (LILACS), Banco de Dados em Enfermagem (BDENF), além de dados da biblioteca virtual Scientific Eletronic Library Online (SciELO). Foram utilizados os descritores: Professores, Absenteísmo, Licença médica e Saúde do trabalhador. Tendo como recorte temporal artigos publicados de 2015 a 2019, disponíveis em inglês, português e espanhol. Resultados: A pesquisa sobre absenteísmo por professores evidenciou que os motivos que mais levaram ao abandono do trabalho foram problemas de saúde, segundo os estudos analisados, os problemas emocionais (22\%), respiratórios (17\%) e desvalorização (9\%) também foram apontados. Os problemas vocais e a sobrecarga de trabalho correspondem a $26 \%$ das causas evidenciadas na pesquisa. As condições de trabalho às quais os docentes estão submetidos em algumas ocasiões acabam por provocar o adoecimento e posteriormente o afastamento da função. Considerações finais: A falta de interesse dos alunos, falta de apoio institucional e de reconhecimento dos seus esforços são outros fatores que também contribuem para o afastamento do trabalho.

Palavras-chave: Professores, Absenteísmo, Licença médica, Saúde do trabalhador.

\section{ABSTRACT}

Objective: To identify in the literature the main causes of absenteeism by teachers. Methods: Integrative review, data collection was carried out from July to November 2019, using via the Virtual Health Library (VHL) the Latin American Health Sciences Literature (LILACS), Nursing Database (BDENF) and data from the Virtual Scientific Electronic Library Online (SciELO) databases. The descriptors were used to conduct the survey: Teachers, Absenteeism, Medical License and Worker Health. The time period of the survey was from 2015 to 2019 . The articles were available in English, Portuguese and Spanish. Results: The research on absenteeism by teachers showed that the reasons that most led to the abandonment of work were health problems, according to the studies analyzed, emotional $(22 \%)$, respiratory $(17 \%)$ and devaluation $(9 \%)$ also problems were pointed out. Vocal problems and work overload corresponded to $26 \%$ of the causes evidenced in the survey. The working conditions to which teachers are submitted on some occasions end up causing them to become ill and later to withdraw from the function. Final considerations: The lack of interest of students, lack of institutional support and recognition of their efforts are other factors that also contribute to the removal from work.

Keywords: Teachers, Absenteeism, Medical leave, Workers' health.

\section{RESUMEN}

Objetivo: Objetivo: Identificar en la literatura las principales causas del ausentismo de los profesores. Métodos: Revisión integradora, la recolección de datos fue realizada de julio a noviembre de 2019, utilizando a través de la Biblioteca Virtual en Salud (BVS) la Literatura Latinoamericana en Ciencias de la Salud (LILACS), la Base de Datos de Enfermería (BDENF) y datos de las bases de datos de la Biblioteca Científica Virtual en Línea (SciELO). Los

\footnotetext{
1 Instituto de Ensino Superior Múltiplo (IESM), Timon - MA. *E-mail: enftatyannesr@gmail.com

${ }^{2}$ Faculdade integral Diferencial (FACID), Teresina - PI.

${ }^{3}$ Faculdade de Tecnologia e Educação Superior Profissional (FATESPI), Teresina - PI.

${ }^{4}$ Universidade Federal do Piauí (UFPI), Teresina - PI.
} 
descriptores fueron utilizados para la realización de la encuesta: Profesores, Ausentismo, Licencia Médica y Salud del Trabajador. El período de tiempo de la encuesta fue de 2015 a 2019. Los artículos estaban disponibles en inglés, portugués y español. Resultados: La investigación sobre el ausentismo de los profesores mostró que las razones que más llevaron al abandono del trabajo fueron los problemas de salud, según los estudios analizados, se señalaron problemas emocionales (22\%), respiratorios (17\%) y de devaluación (9\%). Los problemas vocales y la sobrecarga de trabajo correspondieron al $26 \%$ de las causas evidenciadas en la encuesta. Las condiciones de trabajo a las que se someten los profesores en algunas ocasiones terminan por provocarles una enfermedad y posteriormente el abandono de la función. Consideraciones finales: La falta de interés de los alumnos, la falta de apoyo institucional y el reconocimiento de sus esfuerzos son otros factores que también contribuyen al retiro del trabajo.

Palabras clave: Profesores, Absentismo, Licencia médica, Salud de los trabajadores.

\section{INTRODUÇÃO}

O trabalho tem por conceito o procedimento de interação, que acontece entre o homem e a natureza, onde aquele age intencionalmente sobre elementos desta, transformando-os e dando-lhes forma de maneira que seja útil à vida humana. Ao agir sobre o material, o homem desenvolve nele o que já havia conscientemente planejado, submetendo-o assim à sua vontade (BONFATTI RG, et al., 2017).

O professor tem sido cada vez mais chamado a exercer funções que vão além da sala de aula, como participar efetivamente da gestão escolar, a integrar- se com a comunidade, atender as carências de pais e alunos que causam impacto no desempenho escolar. Isso a longo prazo, resulta em um acréscimo na produção de trabalho não reconhecidos, seja por meio de ampliação da jornada remunerada para as atividades fora da sala de aula, seja por meio da elevação dos rendimentos, impondo ao professor uma atuação cada vez mais polivalente, e flexível para o cumprimento de uma lista cada vez mais extensa e diversificada de tarefas (COSTA AC e FREITAS RG, 2017).

As salas de aula com superlotação, a precariedade de recursos materiais, assim como as pressões advindas das relações interpessoais fazem da docência uma profissão complexa e extremamente estressante, o que a torna uma profissão de alto risco para o desenvolvimento de problemas de saúde e consequente faltas ao trabalho. Além disso, a sensação de frustração com o trabalho docente pode levar os professores a desenvolver sintomas psicossomáticos como a insônia, a hipertensão e depressão (VIDAL ERF, 2017).

O papel do professor não é mais dirigido apenas ao processo de ensino-aprendizagem dos alunos, mas outras estruturas organizacionais necessitam da função do trabalho docente, entre elas a própria comunidade, os pais dos alunos e gestão escolar. Portanto, o fracasso do professor em desempenhar o seu papel principal advém também de forças externas que complicam o desenvolvimento do seu senso crítico e reflexivo sobre sua atuação, algumas vezes podando a sua autonomia. Deste modo, os professores acabam por entrar em conflito, aceitando seu insucesso frente algumas situações e aumentando o número de afastamentos da sala de aula (SOUZA A e LEITE YUR, 2018).

Absenteísmo é uma palavra de origem francesa, que significa literalmente a ausência do trabalho por diversos motivos, sejam eles propositais ou devidos a circunstâncias alheias à vontade do trabalhador. No seu sentido mais amplo, o absenteísmo dos docentes é o resultado da soma dos períodos em que o professor se encontra ausente, sendo a ausência motivada por problemas de saúde ou licença legal. A ausência de professores nas escolas acarreta efeitos extremamente negativos sob o ponto de vista da qualidade e aproveitamento do trabalho pedagógico. Neste sentido, o absenteísmo escolar de docentes ocorre em proporções que influenciam as dinâmicas da escola, sendo o principal fenômeno evidenciado como desarticulador das relações humanas (OLIVEIRA AA, et al., 2020).

O absenteísmo é definido como a ausência do empregado ao trabalho, um fenômeno complexo e de múltipla etiologia, que inclui fatores individuais e relacionados ao ambiente e à organização do trabalho. Quando a falta ao serviço é causada por motivo de doença certificada por licença médica, é chamada de absenteísmo-doença, sendo considerada um importante indicador das condições de saúde dos trabalhadores (LEÃO AL, et al., 2015). 
Um fator levantado sobre a realidade do adoecimento e consequente abandono do trabalho é a intensificação do trabalho docente. Na Lei de Diretrizes e Bases da educação (LDB), as atribuições dos professores vão além da sala de aula. Este profissional também está em constante relação com a comunidade, participando da gestão da escola e do planejamento pedagógico. A intensificação também se dá pela cobrança constante por produção, diminuição do corpo efetivo sem mudança de produção, o que ocorre frequentemente com a dispensa dos profissionais contratados (SANTANA FAL e NEVES IR, 2017).

Os afastamentos de professores relacionados à saúde ocorrem frequentemente e por longos períodos, de forma recorrente e pelos mesmos motivos. Sua volta ao trabalho acarreta piora dos sintomas, o que sugere que seu retorno à escola acontece em condições parecidas às que influenciaram o afastamento (BOTTEGA CG e PEDROSO R, 2018).

No que diz respeito aos direitos dos professores, temos uma contradição em que, ao tempo em que identifica- se um fortalecimento da legislação que controla seus atos trabalhistas ocorre uma intensificação do absenteísmo por parte deste grupo. A precariedade das condições de trabalho, sobretudo devido ao crescimento de contratos temporários nas redes públicas de ensino, a decadência salarial, a perda de garantias trabalhistas e previdenciárias têm tornado cada vez mais agudo o quadro de instabilidade e precariedade do emprego no magistério público (COSTA AC e FREITAS RG, 2017).

Um importante reflexo da precariedade das diversas condições de trabalho dos professores pode ser observado no aumento do índice de problemas de saúde docente, o que se pode chamar de morbidade. Tal consequência se concretizou no que conhecemos como o mal-estar docente, cujo cenário descrito resulta em diferentes doenças somáticas e/ou laborais que são incorporadas em um ciclo vicioso de precarização por causarem o absenteísmo e também o abandono docente e, desta forma alimentar uma série de substituições destes profissionais nas escolas (OLIVEIRA ME, 2019).

Esse "mal estar" acarreta diversos danos aos professores e a sua atuação, dentre eles os sintomas de ordem profissional, os quais destacam-se a irresponsabilidade no planejamento da aula, a falta de zelo na realização das tarefas, a queda na capacidade criativa e de simpatizar com os alunos e a diminuição de expectativa quanto ao seu futuro. Não obstante, a falta de progresso apresentado pelos alunos ou outros possíveis problemas com origem em seu ambiente de trabalho poderão causar eventos frustrantes e estressores na vida do professor (VIDAL ERF, 2017).

Assim, a presente pesquisa justifica-se pela notória desvalorização da profissão de professor, decorrente das más condições de trabalho e do crescente desrespeito sofrido por esse profissional em sala de aula, além da péssima remuneração, o que resulta em um crescimento alarmante do absenteísmo no trabalho, tanto por motivos médicos, como uma forma de fuga e de autopreservação. Diante do que foi exposto o objetivo deste estudo é identificar na literatura as principais causas de absenteísmo por professores.

\section{MÉTODOS}

Trata-se de uma revisão integrativa da literatura, caracterizada como um método de investigação em materiais já publicados, com a finalidade de buscar informações no contexto teórico e empírico bem como em estudos com diferentes abordagens metodológicas (MENDES KDS, et al., 2019).

Para a construção e análise, foi realizada oito etapas, a fim de se obter um melhor entendimento sobre a temática. As etapas para construção dessa revisão foram: identificação do tema e seleção da questão de pesquisa, busca nas bases de dados digitais, estabelecimento de critérios para inclusão e exclusão de estudos, busca dos textos na íntegra, definição das informações a serem extraídas dos estudos selecionados, categorização e avaliação dos estudos incluídos, interpretação dos resultados e apresentação da revisão síntese do conhecimento.

A questão de pesquisa foi organizada de acordo com a estratégia PICO (P: População; I: Intervenção; C: Comparação; O: Desfecho). Portanto, foi sintetizada a seguinte estrutura: P - Professores; I - Absenteísmo; C - Sem comparação; O - Principais causas. Assim, formulou-se a seguinte questão norteadora: Quais as principais causas do absenteísmo por professores? 
A coleta dos dados foi realizada no período de julho a novembro de 2019, utilizando via Biblioteca Virtual em Saúde (BVS) as bases de dados Literatura Latino-Americana em Ciências de Saúde (LILACS), Banco de Dados em Enfermagem (BDENF) além de dados da biblioteca virtual Scientific Eletronic Library Online (SciELO). Para realizar o levantamento dos dados, foram utilizados os seguintes descritores, de acordo com Decs Bireme: Professores, Absenteísmo, Licença médica e Saúde do trabalhador.

Após o levantamento das publicações os resumos foram lidos e analisados. Os critérios de inclusão foram: textos completos, disponíveis on-line, no idioma português, inglês e espanhol, estudos relacionados ao absenteísmo por professores.

Os critérios de exclusão dos artigos foram os estudos de revisão de literatura, teses, dissertações e cartas ao editor, bem como estudos que não contemplavam professores ou abordassem o professor em outro contexto. Dentre os artigos selecionados através do resumo, após leitura dos mesmos, foram utilizados para a pesquisa apenas artigos que se referem diretamente ao tema. Desta forma, a amostra final incluída na categorização dos resultados foi de 11 estudos. Cabe referir que todos os artigos foram lidos na íntegra, visando maior compreensão dos mesmos (Figura 1).

Figura 1 - Fluxograma da aplicação das etapas dos critérios de incluso e exclusão dos artigos para amostra final.

\begin{tabular}{|c|c|c|}
\hline $\begin{array}{l}\text { Estudos pesquisados } \\
\text { nas bases de dados para } \\
\text { formulação dos } \\
\text { resultados: } \\
\text { LILACS: } 322 \\
\text { SCIELO: } 58\end{array}$ & $\begin{array}{l}1^{a} \text { Exclusão: Artigos } \\
\text { duplicados, com metodologia } \\
\text { de revisão: } \\
\text { LILACS: } 119 \\
\text { SCIELO: } 32 \\
\text { BDENF: } 19\end{array}$ & $\begin{array}{l}2^{a} \text { Exclusão: Artigos que } \\
\text { não abordavam absentismo } \\
\text { por professores: } \\
\text { LILACS: } 23 \\
\text { SCIELO: } 11 \\
\text { BDENF: } 10\end{array}$ \\
\hline
\end{tabular}

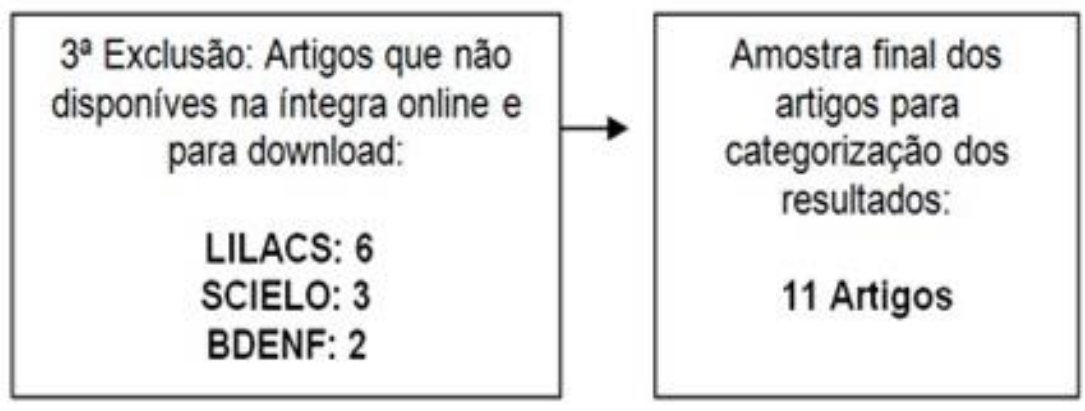

Fonte: PORTO TNRS, et al., 2020.

O formulário para coleta de dados foi preenchido para cada artigo da amostra final do estudo. O formulário previamente elaborado pelas atoras permitiu a obtenção de informações sobre identificação do estudo: Autores, Periódico e ano de publicação, Tipo de estudo/ Metodologia, População do estudo, Principais causas do absenteísmo e Qualis Capes.

\section{RESULTADOS E DISCUSSÃO}

Os resultados desta pesquisa evidenciam que a necessidade do professor se ausentar da sala de aula não está associada com a falta de comprometimento com a educação dos alunos. Os maiores motivos de faltas dos professores no trabalho foram registrados por problemas com a saúde ou relacionados a carga de trabalho. As condições de trabalho às quais os docentes estão submetidos em algumas ocasiões acabam por provocar o adoecimento e posteriormente o afastamento da função. 
Estudos realizados neste sentido, mostram que o absenteísmo escolar dos professores causa uma quebra na continuidade do trabalho pedagógico. Ou seja, as dinâmicas normais do ensino são colocadas em xeque com a ausência sistemática e cada vez mais frequente de professores nos seus estabelecimentos de ensino.

A ausência nos seus locais de trabalho causa uma ruptura do fluxo regulatório de eventos dentro da sala de aula, o que acaba por gerar problemas diretos nos alunos, como a baixa adesão ao ensino e queda do rendimento escolar (OLIVEIRA ME, 2019).

O absenteísmo causa prejuízos não apenas aos professores, mas também à qualidade da educação e aos seus principais indicadores, esta prática vem se tornando cada vez mais frequente, principalmente entre professores do ensino público, devido as precárias condições de trabalho, a crescente desvalorização profissional e as violências sofridas em sala de aula.

A pesquisa sobre absenteísmo por professores evidenciou que os motivos que mais levaram ao abandono do trabalho foram problemas de saúde, segundo os estudos analisados, os problemas emocionais (22\%), respiratórios (17\%) e desvalorização (9\%) foram apontados. Os problemas vocais e a sobrecarga de trabalho correspondem a $26 \%$ das causas evidenciadas na pesquisa (Gráfico 1).

Gráfico 1 - Análise das principais causas do absenteísmo por professores.

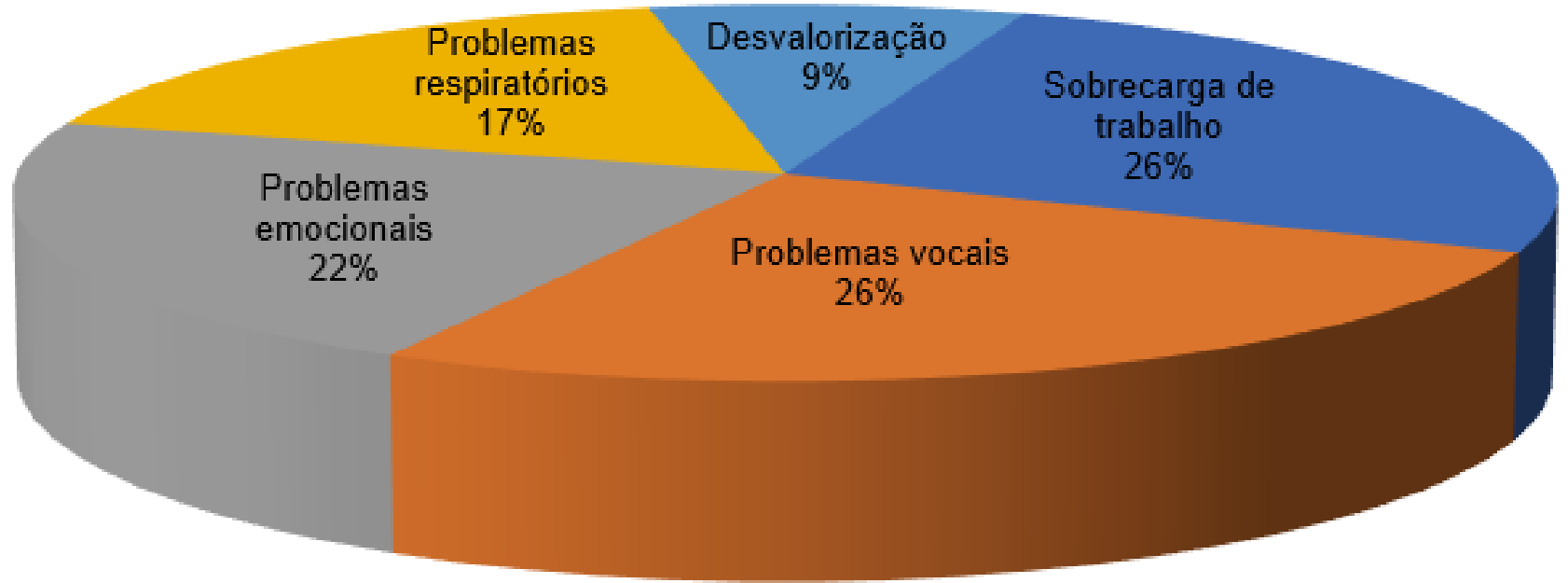

Fonte: PORTO TNRS, et al., 2020.

Para facilitar a compreensão da temática, construiu-se um quadro contendo as características metodologias e principais resultados dos artigos, o que possibilita ao leitor melhor compreensão e avaliação da aplicabilidade da revisão (Quadro 1). 
Quadro 1 - Caracterização segundo: Autores, Periódico /Ano de publicação, Tipo de estudo/Metodologia, População do estudo, Principais causas do Absenteísmo e qualis capes.

\begin{tabular}{|c|c|c|c|c|c|c|}
\hline $\begin{array}{l}N^{\circ} \text { do } \\
\text { Estudo }\end{array}$ & Autor(es) & $\begin{array}{l}\text { Períodico/ Ano de } \\
\text { Publicação }\end{array}$ & $\begin{array}{l}\text { Tipo de Estudo/ } \\
\text { Metodologia }\end{array}$ & $\begin{array}{l}\text { População do } \\
\text { Estudo }\end{array}$ & Principais Causas do Absenteísmo & $\begin{array}{l}\text { Qualis } \\
\text { Capes }\end{array}$ \\
\hline 1 & $\begin{array}{l}\text { SILVEIRA MLL, et } \\
\quad \text { al., } 2015\end{array}$ & $\begin{array}{c}\text { Revista de } \\
\text { Linguagens, Artes e } \\
\text { Estudos em Cultura/ } \\
2015\end{array}$ & $\begin{array}{l}\text { Pesquisa } \\
\text { exploratória e } \\
\text { quantitativa }\end{array}$ & $\begin{array}{l}\text { Professoras da } \\
\text { educação infantil }\end{array}$ & $\begin{array}{l}\text { Problemas viróticos, emocionais, respiratórios } \\
\text { e vocais. }\end{array}$ & B2 \\
\hline 2 & $\begin{array}{l}\text { POSSATO BC } \\
2018\end{array}$ & $\begin{array}{l}\text { Caderno de Pesquisa/ } \\
2018\end{array}$ & $\begin{array}{l}\text { Pesquisa } \\
\text { etnográfica }\end{array}$ & $\begin{array}{l}\text { Professores do } \\
\text { ensino médio }\end{array}$ & $\begin{array}{l}\text { Degradação salarial, sobrecarga de trabalho, } \\
\text { falta de valorização de projetos inovadores. }\end{array}$ & A1 \\
\hline 3 & $\begin{array}{l}\text { MOREIRA DL, et } \\
\quad \text { al., } 2017\end{array}$ & $\begin{array}{l}\text { Revista Gestão \& } \\
\text { Conexões/ } 2017\end{array}$ & $\begin{array}{l}\text { Pesquisa descritiva } \\
\text { de abordagem } \\
\text { quantitativa }\end{array}$ & $\begin{array}{l}\text { Professores do } \\
\text { ensino fundamental }\end{array}$ & $\begin{array}{l}\text { Tempo de profissão, sobrecarga, e } \\
\text { relacionamento entre colegas de trabalho. }\end{array}$ & B4 \\
\hline 4 & $\begin{array}{l}\text { CARLOTTO MS, } \\
\text { et al., } 2019\end{array}$ & $\begin{array}{l}\text { Psicologia UNISC/ } \\
2019\end{array}$ & $\begin{array}{l}\text { Estudo descritivo } \\
\text { retrospectivo }\end{array}$ & $\begin{array}{l}\text { Professores de } \\
\text { educação infantil e } \\
\text { fundamental }\end{array}$ & $\begin{array}{l}\text { Transtornos neuróticos, transtornos } \\
\text { relacionados com o "stress" e transtornos } \\
\text { somatoformes e transtornos do humor. }\end{array}$ & B1 \\
\hline 5 & $\begin{array}{l}\text { SOUZA CM, et } \\
\quad \text { al., } 2017\end{array}$ & $\begin{array}{l}\text { Revista Bras Medicina } \\
\text { Trabalho/ } 2017\end{array}$ & Estudo retrospectivo & $\begin{array}{l}\text { Professores sob } \\
\text { licença médica }\end{array}$ & Nódulos vocais, disfonia e Cistos & B2 \\
\hline
\end{tabular}

REAS/EJCH | Vol.13(1) | e5135 | DOI: https://doi.org/10.25248/reas.e5135.2021 Página 6 de 10 
Revista Eletrônica Acervo Saúde / Electronic Journal Collection Health | ISSN 2178-2091

\begin{tabular}{|c|c|c|c|c|c|c|}
\hline $\begin{array}{l}N^{\circ} \text { do } \\
\text { Estudo }\end{array}$ & Autor(es) & $\begin{array}{l}\text { Períodico/ Ano de } \\
\text { Publicação }\end{array}$ & $\begin{array}{l}\text { Tipo de Estudo/ } \\
\text { Metodologia }\end{array}$ & $\begin{array}{l}\text { População do } \\
\text { Estudo }\end{array}$ & Principais Causas do Absenteísmo & $\begin{array}{l}\text { Qualis } \\
\text { Capes }\end{array}$ \\
\hline 6 & $\begin{array}{l}\text { MEDEIROS AM e } \\
\text { VIEIRA MT, } 2019\end{array}$ & $\begin{array}{l}\text { Caderno de Saúde } \\
\text { Pública/ } 2019\end{array}$ & Estudo Transversal & $\begin{array}{l}\text { Professores da } \\
\text { Educação básica }\end{array}$ & $\begin{array}{c}\text { Problema emocional, problema respiratório e } \\
\text { distúrbios vocais }\end{array}$ & A1 \\
\hline 7 & $\begin{array}{l}\text { SIMÕES AR e } \\
\text { HUPTY HJ, } 2015\end{array}$ & $\begin{array}{l}\text { Metropolitana de } \\
\text { Relato Profissional/ } \\
2015\end{array}$ & $\begin{array}{l}\text { Pesquisa } \\
\text { exploratória de } \\
\text { abordegem } \\
\text { qualitativa }\end{array}$ & $\begin{array}{l}\text { Professores do } \\
\text { Ensino Superior }\end{array}$ & Distúrbios da voz & B4 \\
\hline 8 & $\begin{array}{l}\text { FERREIRA LM, } \\
\quad 2019\end{array}$ & $\begin{array}{l}\text { Caderno de Saúde } \\
\quad \text { Pública/2019 }\end{array}$ & $\begin{array}{l}\text { Pesquisa } \\
\text { exploratória de } \\
\text { abordagem } \\
\text { qualitativa }\end{array}$ & $\begin{array}{l}\text { Professores das } \\
\text { redes pública e } \\
\text { privada }\end{array}$ & $\begin{array}{l}\text { Condições de trabalho, sobrecarga de } \\
\text { trabalho, agregação de tarefas de professores } \\
\text { ausentes. }\end{array}$ & A1 \\
\hline 9 & $\begin{array}{l}\text { MAIA EG, et al., } \\
2019\end{array}$ & $\begin{array}{l}\text { Caderno de Saúde } \\
\text { Pública/2019 }\end{array}$ & Estudo Transversal & $\begin{array}{l}\text { Professores da } \\
\text { Educação básica }\end{array}$ & $\begin{array}{l}\text { Problemas de saúde, a percepção de alta } \\
\text { exigência das tarefas, indisciplina dos alunos, } \\
\text { ruído intenso no ambiente de trabalho. }\end{array}$ & A1 \\
\hline 10 & $\begin{array}{l}\text { ASSUNÇÃO AA e } \\
\text { ABREU MNS, } \\
2019\end{array}$ & $\begin{array}{l}\text { Caderno de Saúde } \\
\text { Pública/2019 }\end{array}$ & $\begin{array}{l}\text { Pesquisa } \\
\text { exploratória de } \\
\text { abordagem } \\
\text { qualitativa }\end{array}$ & $\begin{array}{l}\text { Professores da } \\
\text { Educação básica }\end{array}$ & $\begin{array}{l}\text { Fraco apoio social, ambiente agitado em } \\
\text { função da indisciplina dos alunos, pior } \\
\text { autoavaliação de saúde e problema de saúde } \\
\text { considerado doença ocupacional. }\end{array}$ & A1 \\
\hline 11 & $\begin{array}{l}\text { NEVES MY, et } \\
\text { al., } 2019\end{array}$ & $\begin{array}{l}\text { Caderno de Saúde } \\
\text { Pública/2019 }\end{array}$ & Estudo Transversal & $\begin{array}{l}\text { Professoras do } \\
\text { Ensino Fundamental }\end{array}$ & $\begin{array}{l}\text { Relações hierárquicas conflituosas, horário } \\
\text { extenso e mal estruturado de trabalho } \\
\text { (somado ao trabalho doméstico invisibilizado) }\end{array}$ & A1 \\
\hline
\end{tabular}

Fonte: PORTO TNRS, et al., 2020.

REAS/EJCH | Vol.13(1) | e5135 | DOI: https://doi.org/10.25248/reas.e5135.2021 Página 7 de 10 
O docente está inserido em uma microestrutura, representada pela escola constituída por seus pares, diretoria, alunos e também em uma macroestrutura, representada pela secretaria de educação e em políticas educacionais, onde o sofrimento se mostra de diferentes formas, diante das situações desfavoráveis das atividades exercidas estes professores tentam amenizar este sofrimento desenvolvendo diversas técnicas de enfrentamento.

Como por exemplo: mudança nas regras de ensino, incentivo do trabalho e equipe e reconhecimento do trabalho realizado pelos alunos, desta forma possibilitando a construção do prazer no trabalho e preservado sua saúde, transformando suas angústias em força e estimulando a mudança. Porém, nem todos os professores têm conseguido se manter com saúde para continuar exercendo a arte de ensinar (MOTA LG e NEVES IR, 2017).

Em relação aos casos de afastamento por distúrbios da voz, dos 153 professores afastados por disfonia, a maior prevalência de distúrbios vocais acometeu o gênero feminino $(96,7 \%)$. Os nódulos vocais predominaram no diagnóstico, perfazendo $(40 \%)$ das lesões vocais. A média de dias de afastamento foi de 120. Cerca de $(55 \%)$ dos professores em licença médica estavam com restrição de função e ficaram em média 166 dias afastados. Levando em consideração o tempo de licença médica desses profissionais, constatou-se que (86\%) ficaram afastados da atividade laboral por um período de até 6 meses (SOUZA CM, et al., 2017).

Resultado parecido foi encontrado por Medeiros AM e Vieira MT (2019) que constatou que o principal motivo de afastamento foi o distúrbio de voz $(17,7 \%)$, já em contrapartida a duração da maioria dos afastamentos (78\%) durou apenas sete dias. A maior prevalência de licenças por distúrbio vocal ocorreu entre os professores das regiões Nordeste e Norte.

Para além das doenças laborais mais frequentes ligadas à profissão, como os problemas de voz, os professores também apresentam índices altos de doenças psicossomáticas relacionadas ao estresse e a depressão. Destaca- se as relações entre o aumento das atribuições e das responsabilidades docentes com demais mecanismos e estratégias que os docentes incorporam no seu ambiente de trabalho afim de darem conta de atuar neste cenário precário, convivendo com a explícita e constante desvalorização, as cobranças exacerbadas, a violência em sala de aula e ainda assim imprimir lógicas funcionais ao cotidiano (OLIVEIRA ME, 2019).

A falta de percepção dos professores a respeito da sua saúde vocal, principalmente no início dos sintomas que caracterizam os primeiros indícios de problemas vocais, resultam no atraso do diagnóstico e na busca por ajuda profissional. Esta resistência em buscar ajuda e permanecer lecionando pode ser justificada pelas questões econômica do professor, mesmo que esse profissional seja do setor público, com uma certa estabilidade no trabalho, onde a licença para tratamento de problemas de saúde está amparada pela lei federal sem que haja um prejuízo da sua remuneração. Existe, porém, essa resistência em escolher esse caminho diante das dificuldades burocráticas para se conseguir tal licença (FILHO FAP, et al., 2020).

Outra justificativa para a conduta dessa classe profissional está na grande tolerância em falar, mesmo com o comprometimento vocal. Pressupõe- se que o docente desenvolva, no decorrer da carreira, diversas estratégias com o objetivo de minimizar a sobrecarga sobre a voz, permitindo desta forma que consiga lidar melhor com tais distúrbios (FILHO FAP, et al., 2020).

Maia EG et al. (2019) em sua pesquisa, cerca de $(70 \%)$ dos professores reportaram faltas ao trabalho por pelo menos um dia no ano. Problemas de saúde foram a causa mais frequente das ausências, acometendo mais da metade $(53,34 \%)$ dos professores. Já entre os fatores de risco para as faltas ao trabalho, a sobrecarga foi o mais prevalente $(81,59 \%)$, seguido pelo estresse devido à indisciplina dos alunos $(70,17 \%)$ e $(64,02 \%)$ pelo ruído intenso no ambiente de trabalho. Destacando também a desvalorização e falta de apoio na escola $(40,63 \%)$.

A prevalência de percepção de pressão laboral se mostrou mais elevada entre professores que tem mais de um emprego (57\%), que dão aula em escolas estaduais $(57,5 \%)$, com jornada de trabalho prolongada $(56,2 \%)$, pouco apoio social $(62,3 \%)$, ambiente escolar devido a indisciplina dos alunos $(63,7 \%)$ e ruídos $(64,6 \%)$ (ASSUNÇÃO AA e ABREU MNS, 2019). 
Em estudo desenvolvido no Rio de Janeiro, sobre os fatores que contribuem para a sobrecarga de trabalho. Destacou que o trabalho realizado pelas professoras ultrapassa os limites da jornada de trabalho estipulada, ou seja, elas ficam na escola atuando em funções aquém dos seus deveres (NEVES MY, et al., 2019).

Segundo o estudo de Silveira MLL, et al. (2015) com 608 professoras (40,95\%) afirmaram que já tiraram licença no período de três anos. Do total que estiveram em licença de saúde, (47\%) tiraram uma vez, $(22,9 \%)$ duas vezes, $(10 \%)$ três vezes e $(20,1 \%)$ mais de quatro vezes. Em relação aos principais motivos para os pedidos de licenças de saúde, $(14,73 \%)$ das professoras relataram problemas viróticos, $(10,47 \%)$ por problemas emocionais, $(6,71 \%)$ por problemas respiratórios e $(3,76 \%)$ por problemas vocais. Os dados evidenciaram que mais de $(40 \%)$ das professoras que atuam na escola municipal já se afastaram do trabalho por problemas de saúde.

O autor em sua pesquisa verificou que 47 professores apresentaram ter pedido uma licença com atestado nos últimos dois anos. A média de idade desses professores foi de 48,2 anos, com idade mínima de 33 anos e máximo de 61 anos e mediana foi de 49 anos. O tempo de serviço teve média de 17,7 anos e a mediana foi de 12 anos. Resultado parecido foi encontrado em pesquisa realizada com docentes de escolas de Salvador, mostrou existir uma associação entre a idade superior a 40 anos e as alterações vocais.

Relatam também que possivelmente existe um desgaste vocal originado da exposição frequente a fatores nocivos à saúde da voz. A prevalência dos dirtúbios da voz em docentes com idade superior a 49 anos pode estar associada à uma queda da capacidade vocal que ocorre de forma natural com o aumento da idade (FILHO FAP, et al., 2020). Na pesquisa de Possato BC (2018), os dados encontrados mostram que professores da rede pública são os possuem a pior situação de trabalho, com salários baixos, onde muitos são obrigados a dobrarem sua carga horária e a darem aulas em outras redes de ensino ou trabalhos em uma área diferente da sua formação para completar o salário.

Já no de Moreira DL, et al. (2017), evidenciou que a maioria dos professores que se afastaram do trabalho, são mulheres, com a faixa etária de 41 anos de idade, casadas e com até 2 filhos. São profissionais pósgraduadas e que atuam na docência há mais de 10 anos e trabalham em média 32 horas semanais com turmas do ensino fundamental da rede pública. Dentre a população média de trabalhadores do estudo de Carlotto MS, et al. (2019) foram identificados 2.931 afastamentos por motivos médicos entre os anos de 2012 e 2016. Desses, 116 docentes apresentaram afastamentos por motivos de saúde emocional, totalizando 246 licenças.

Desta forma, a prevalência de afastamentos do trabalho por problemas de saúde foi de (11\%) em relação à média de trabalhadores e (8\%) em relação aos motivos de afastamento em geral. Em relação ao perfil dos professores, os resultados evidenciaram que, $(94,8 \%)$ eram mulheres, $(51,8 \%)$ eram casados, possuíam filhos (75\%), idade média de 44 anos e 9 meses e tempo de trabalho de 16 anos e 4 meses.

No estudo de Ferreira LM (2019) constatou que foram concedidas 40.578 licenças para tratamento de saúde a 13.408 servidores em uma população média de 17.270 pessoas, que resultou em 944.722 dias de absenteísmo. A prevalência acumulada de absenteísmo-doença foi maior entre as mulheres $(52,0 \%)$ faixa etária superior a 40 anos $(55,9 \%)$, casados $(49,9 \%)$, e professores $(54,7 \%)$, com mais de 10 anos de serviço $(61,9 \%)$ e com múltiplos vínculos de trabalho $(53,7 \%)$.

Pesquisa realizada com o objetivo de conhecer os fatores que influenciam o absenteísmo escolar nas escolas primárias nos distritos de Gilé e lle, mostrou que o principal fator foi a procura de instituições bancárias para o saque do salário (45\%), seguido pela necessidade de aperfeiçoamento na área que ensina (45\%), problemas de saúde e outros motivos corresponderam a (5\%). Tal pesquisa mostra a grande diferença dos motivos em relação aos professores brasileiros (OLIVEIRA AA, et al., 2020).

Muitos professores têm sentido o seu trabalho sofrer com o desgaste, além da intensificação, com o processo ascendente de proletarização tendo como resultado o aumento de seu ritmo laboral e no volume das atividades em contraponto com a maior precarização das condições de trabalho, entre elas o salário. Esta situação acaba levando os professores à insegurança, a refletirem sobre sua prática na vida escolar. $O$ aumento do estresse e o desenvolvimento de outros problemas de saúde, além da impossibilidade de aperfeiçoamento e a falta de tempo para preparação e reflexão critíca sobre o seu trabalho são os resultados deste quadro (MOTA LG e NEVES RV, 2020). 
Se as doenças que constantemente acomete docentes fossem todas registradas no Sinan, provavelmente teríamos um cenário mais claro da frequência de adoecimento desses profissionais. Assim, é necessário construir um outro modo de pensar em gestão em saúde, desta forma convivendo e reconhecendo a autonomia dos trabalhadores, desenvolvendo diferentes formas de controle sobre o trabalho na perspectiva dos usuários, considerando o saber de cada um sobre saúde (FILHO FAP, et al., 2020).

\section{CONSIDERAÇÕES FINAIS}

Foram várias as causas apontadas neste estudo para o absenteísmo de professores, entre eles, os problemas respiratórios, problemas emocionais, problemas vocais e a sobrecarga de trabalho. A falta de interesse dos alunos, falta de apoio institucional e de reconhecimento dos seus esforços são outros fatores que também contribuem para o afastamento do trabalho. Identificar as principais causas de faltas ao trabalho por professores ofereceu pistas para que haja uma definição de prioridades nas intervenções e nas políticas públicas educacionais. Destaca- se a necessidade de cuidados com a voz, apoio das autarquias educacionais e um melhor dimensionamento das atividades que resultariam em um menor índice de absenteísmo. Pesquisas futuras são necessárias para uma maior compreensão dos resultados que identificaram na literatura as principais causas do absenteísmo por professores, visando a formulação de estratégias de prevenção e de enfrentamento que auxiliem o docente frente a esta problemática.

\section{REFERÊNCIAS}

1. ASSUNÇÃO AA, ABREU MNS. Pressão laboral, saúde e condições de trabalho dos professores da Educação Básica no Brasil. Cad. Saúde Pública, 2019;35(Sup):1-16.

2. BOTTEGA CG, PEDROSO R. Saúde Mental dos Professores da Rede de Ensino Público e Gestão: uma relação possível? Revista Ciências do Trabalho, 2018;3(13):59-73.

3. BONFATTI RJ, et al. Ergonomia, desenvolvimento e trabalho sustentável: um olhar para a saúde do trabalhador. Rev Bras Med Trab, 2017;15(3):257-66.

4. CARLOTTO MS, et al. Prevalência de Afastamentos por Transtornos Mentais e do Comportamento Relacionados ao Trabalho em Professores. PSI UNISC, 2019;3(1):19-32.

5. COSTA AC, FREITAS RG. A "economia dos direitos" laborais em professores do ensino básico: os dilemas entre o absenteísmo e os condicionantes para a progressão na carreira. Revista Labor, 2017;1(18):90-104.

6. FERREIRA LM. Lições de professores sobre suas alegrias e dores no trabalho. Cad. Saúde Pública, 2019;35(Sup):1-11.

7. FILHO FAP, et al. Prevalência do absenteísmo por distúrbios vocais entre professores. Bionorte, 2020;9(1):20-5.

8. LEÃO AL, et al. Absenteísmo-doença no serviço público municipal de Goiânia. Rev bras epidemiol., 2015;18(1):262-277

9. MAIA EG, et al. Múltiplas exposições ao risco de faltar ao trabalho nas escolas da Educação Básica no Brasil. Cad. Saúde Pública, 2019;35(Sup):1-13.

10. MEDEIROS AM, VIEIRA MT. Ausência ao trabalho por distúrbio vocal de professores da Educação Básica no Brasil. Cad. Saúde Pública, 2019;35(Sup):1-12.

11. MENDES KDS, et al. Uso de gerenciador de referências bibliográficas na seleção dos estudos primários em revisão integrativa. Texto contexto- enfermagem, 2019;28. Epub 14.

12. MOREIRA DL, et al. Síndrome de burnout: estudo com professores da rede pública da cidade de Farroupilha no Rio Grande do Sul. Revista Gestão \& Conexões, 2017;5(2):41- 63.

13. MOTA LG, PIRES RV. Trabalho docente: um estudo da psicodinâmica do trabalho em colégio. Braz. J. of Bus, 2020;2(10: 195-206.

14. NEVES MY, et al. A saúde das professoras, os contornos de gênero e o trabalho no Ensino Fundamental. Cad. Saúde Pública, 2019;35(Sup):1-16.

15. OLIVEIRA AA, et al. O absenteísmo escolar dos/as professores/as nas escolas primárias da província da Zambézia em Moçambique (2015-2016): uma análise das suas implicações. Rev. Ed. Popular, 2020;19(1):144-159.

16. OLIVEIRA ME. "Piorou a diabetes pelo emocional": precarização do trabalho docente e o adoecimento dos professores paulistas. Fronteiras \& Debates, 2019;(1): 109-123.

17. POMPEO DA, et al. Revisão integrativa: etapa inicial do processo de validação de diagnóstico de enfermagem. Acta paul. Enf., 2009;22(4):222-232.

18. POSSATO BC. Absenteísmo e condições de trabalho docente: o que narram os professores?. Cad. Pesq., 2018;25(4):107127.

19. SANTANA FAL, NEVES IR. Saúde do trabalhador em educação: a gestão da saúde de professores de escolas públicas brasileiras. Saúde Soc, 2017;26(3):786-797.

20. SILVEIRA MLL, et al. Mal-estar Docente e Absenteísmo: Uma Relação de Trabalho e Saúde das Professoras de Educação Infantil. Revista de Linguagens, Artes e Estudos em Cultura, 2015;1(2):99-102.

21. SIMÕES AR, HUPTY HJ. Fatores que podem ocasionar distúrbio de voz causando o absenteísmo do professor. Metropolitana de Relato Profissional, 2015;1(2):2-15.

22. SOUZA A, LEITE YUR. Reflexões relacionadas ao trabalho do professor nas escolas públicas e o absenteísmo. Colloquium Humanarum, 2018;15(1):119-129.

23. SOUZA CM, et al. Desfecho dos professores afastados da Secretaria de Estado de Educação do Distrito Federal por distúrbios vocais entre 2009-2010. Rev Bras Med Trab. 2017;15(4):324-328.

24. VIDAL ERF. Síndrome burnout em professores. Pedagogia em Ação, 2017;9(1):39-46. 